\title{
PROTECCION DE LOS CAMPOS CONTRA LAS INFILTRACIONES DE LA URBANIZACION DEFECTUOSA
}

Consideramos, para el presente estudio, divididos los terrenos de campo en tres grupos:

I.-Terrenos en campo libre; es decir, no afectados por limitaciones derivadas de los planos de ensanche de poblaciones o de los de acondicionamiento regional.

II.--Terrenos comprendidos en las zonas de dichos ensanches o en las destinadas a la protección de su salubridad: $y$

III.-Los situados en zonas sólo afectadas por planos regionales.

\section{I.-TERrenos EN CAMPo LIBre}

Apreciaremos en este grupo dos casos:

Construcciones aisladas, separadas entre sí por importantes extensiones de teirreno, como las viviendas y construcciones anexas de las colonizaciones agrícolas cuando se emplaza cada una de ellas en la misma parcela que cultivan sus habitantes.

En estos edificios, como en todos los del país, deben no sólo observarse los preceptos generales que rigen la higiene de la vivienda, sino también procurar, mediante inspecciones, que la observancia de dichos preceptos sea permanente, con el fin de evitar que, como acusan las estadísticas sanitarias, la salubridad de la vivienda en el campo, a pesar de las ventajas del medio en que se halla, sea a veces inferior a la de la vivienda ciudadana.

En estas colonizaciones será a veces conveniente, antes de emplazar las construcciones proceder a un reparcelamiento del terreno que haga más conómicos los cultivos.

En el campo debe procurarse que las construcciones a situar cerca 912 de las vías frecuentadas, cuyas distancias a ellas deben fijar los correspon- 
dientes reglamentos, no creen obstáculos a la rapidez de los vehículos. En algunos casos se prohibe que dichas construcciones tengan entrada directa por esias vías, sino por otras próximas que desemboquen en ellas en lugares y formas. convenientes.

Debe evitarse que el aspecto de las construcciones visibles desde vías importantes, carreteras, autopistas y ferrocarriles, así como de las situadas en lugares de singular belleza, frecuentados como sitios de recreo por los habitantes de las poblaciones, aun a veces alejados de tllas, como ciertos parajes propios para el camping o la práctica del esquí, resten atractivos al paisaje.

Agrupaciones concentradas de edificios.-Desde su iniciación, deben tenerse en ellas en cuenta, además de lo antes indicado, los efectos de la proximidad entre las edificaciones, para evitar a sus habitantes las molestias o perjuicios que de ella puedan derivarse. Puede ello regularizarse mediante ordenanzas de carácter general,

Al desarrollarse el núcleo urbano aparece la necesidad de abrir nuevas vías, establecer servicios de carácter colectivo -abastecimiento de agua potable, desagües, iluminación, etc.-, disponer alguna plaza donde se procure ir agrupando los edificios de carácter público que se vayan necesitando. Al llegar a determinado número de habitantes convendrá dedicar, con carácter permanente, terremo a necesidades deportivas. Todo ello debería realizarse de acuerdo con proyectos, parciales o de conjunto, estudiados por técnicos competentes.

\section{II.-Terrenos de campo próximos a núcleos urbanos importantes}

Para evitar que en terrenos de este grupo aparezcan urbanizaciones que perjurdiquen las condiciones higiénicas de estos nuicleos o el buen desarrollo de su ensanche, son precisas disposiciones munlicipales que, de acuerdo con la legislación vigente, indiquen no sólo dónde y en qué forma debe edificarse, sino también cuándo podrá empezar a construirse en las distintas partes del ensanche. Además, es indispensable que estas disposiciones se tomen oportunamente, para lograr que siempre precedan a las iniciativas constructivas privadas. $\mathrm{Y}$ también que sean castigadas severamente las infracciones de dichas disposiciones.

Plano regulador del ensanche.-Cuando se trate, pues, de poblaciones importantes por su intensidad de vida, como sucede, por ejemplo, en muchos centros industriales, o que hayan alcanzado cierto número de habitantes-ley Cornudet, francèsa-, deben estudiarse siempre planos de ensanche de extensión proporcionada a las necesidades constructivas de cada 
clase de edificación que puedan preverse durante un plazo prudencial, puestas de manifiesto por las estadísticas del icrecimieno anual experimentado por cada una de ellas al formarse la aglomeración existente.

Este plano regulador precisará las zonas donde, según su objeto, deberán colocarse los edificios y su situación respecto a la vía pública. Formarán, pues, parte de este plano la zonización y el de alineaciones y rasantes de las nuevas vías y demás espacios públicos, o sea. $\mathrm{cl}$ de su limitación en planta. y alzado.

La zonización nos determinará, de acuerdo con las circunstancias locales, los emplazamientos más convenientes para los distintos barrios residenciales correspondienties a la densidad o densidades de población previsas, lo que motivará construcciones de diferentes clases $\mathrm{y}$ variados grados de aprovechamiento constructivo del terreno; comerciales; los destinados a instalaciones industriales; los mixtos, etc.; los terrenos que deberán destinarse al establecimiento y eventual ensanche de los servicios públicos, relacionados con la salubridad, abastecimientos, comunicaciones y otros; la situación de los espacios libres permanentes, calculados según las necesidades de la población prevista, etc. Los terrenos que no convenga utilizar, o cuyo mejor destino no pueda de momento precisarse, deberían continuar dedicados a la agricultura, con el carácer de zonas reservadas.

Estos planos convendrá estudiarlos en sus líneas generales con una extensión superior a la exigida por las necesidades previsibles, a fin de llegar en futuros desarrollos a conjuntos bien articulados. El estudio viario detallado sólo debería realizarse para sus partes de próxima edificación; es decir, para aquellas cuyo mejor aprovechamiento sea bien conocido, con lo cual podremos dar a sus calles y manzanas las disposiciones y medidas más adecuadas a su especial destino; la construcción de las vías y demás elementos de estas zonas así detailladas, convendría hacerla gradualmente de acuerdo con las conveniencias colectivas; es decir, inspirándose en una sana política del terreno-no encarecer, facilitando la edificación, terrenos próximos a otros que deban ser adquiridos por el Ayuntamiento, o, al contrario, dirigirla a zonas que convenga poner en marcha, etc.-, prescindiendo de los in:ereses de los que parcelan por especulación, cuando no coinciden con los generales. Se procurará que existan siempre disponibles solares para las diferentes olases de edificación, en cantidad suficiente para evitar aumentos exagerados en el valor de los solares, en perjuicio de la economía de las viviendas futuras.

En el resto del plano sólo convendrá, de momento, fijar los trazados de las vías de enlace, cuya construcción, cuando sea necesaria, podría ini914 ciarse en forma de sencillas carreteras de perfil transversal desarrallable, 
y los emplazamientos de las reservas verdes permanentes para, económicamente, poder preservar a tiempo los terrenos afectados.

Los sectores que en estas zonas apartadas quedarian limitados por estas vías de enlace continuarían con su aprovechamien:o agrícola, reservadas para parcelamientos ulteriores de trazado todavía no determinado.

Más allá, y lindante con la extensión urbanizable del ensache. establecen muchas ciudades cinturones verdes limitando el crecimiento del conjunto urbano; otras disponen sistemas de parques exteriores más o menos apartados. En ambos casos debe asegurarse, mediante compras, servidumbres $\mathrm{u}$ otros medios, la permanencia de estas reservas verdes.

Una vez aprobado un plano regulador, deben siempre hacerse cumplir sus prescripciones. Si un Ayuntamiento juzgara defectuoso un plano vigente de esta clase, debe procurar enmendarlo rápidamenite, aprobando, mediante los trámites legales correspondientes, otro que se considere mejor; pero obligando a respetar el primero mientras no estén aprobadas sus modificaciones.

Edificaciones en el ensanche -Las nuevas construcciones en las zonas de ensanche deben no sólo ajustarse a las alineaciones y ordenanzas allí vigentes, sino también levantarse en solares; es decir, en terremos de naturaleza, forma y dimensiones apropiadas-lo que obliga a menudo a reparcelar las manzanas-, lindantes con vías públicas aprobadas, dotadas a lo menos de pavimentación, canalizacioes de agua potable y desagües, en comunicación directa con la red viaria del núcleo urbano. No autorizando el Ayuntamiento la construcción fuera de tiempo de tales vías, se evita allí la edificación. Si las vías estuvieran aprobadas, pero todavía no se hubieran construido, podría en algún caso de justificado interés público atenuarse el rigorismo antes indicado, permitiendo la edificación, de acuerdo siempre con los tipos de edificación y las alineaciones aprobadas, cuando las construcciones tuvieran salida por algún camino, aun cuando fuera de carácter particular, apto para la circulación rodada-extinción de incendios, etc.-, que enlazase con la red viaria pública y dispusiera siempre de un caudal suficiente de agua potable a distancia cómoda de ellas y de un desagüe de líquidos residuales que no diera lugar a peligros ni molestias para sus habitantes ni para los vecinos. Estas últimas circunstancias, de laboriosa comprobación, aconsejan ser parco en esta clase de autorizaciones.

En los sectores reservados para parcelamientos viarios ulteriones, todavía no determinados, y que deberían continuar con el carácter de terreno agrícola, sólo serían admisibles construcciones sencillas, de una o dos plantas, siempre que por familia que en ellas habitase dispusieran de una extensión de terreno no inferior a la llamada parcela agrícola familiar; es decir, aquella con cuyo cultivo se puede mantener una familia y subvenir a la amor- 
tización del capital empleado en la explotación, incluído el valor de los edificios. Las nuevas edificaciones en estos sectores deberian autorizarse sólo a precario. Se ha propuesto que sólo se permitan en estos sectores edificaciones cuya duración se haya calculado teniendo en cuenta el plazo probable que tardará en realizarse el sistema viario cuyo normal trazado pudieran entorpecer, solución que juzgamos de valor principalmente teórico.

La construcción en estas zonas de edificios destinados a instituciones benéficas, residencias señoriales u otros de análoga importancia, puede ser útil mientras dispongan de superficies de terreno libre realmente generosas; por ejemplo, superiores a las proporciones, respecto a la parte edificada, a las minimas fijadas para cualquier otra zona del ensanche. La formación de grandes parques de propiedad particular debe fomentarse en todo el término municipal.

\section{III.-Limitaciones EN. LA edificación DeRIVADAs DE LOS INTERESes REGIONALES.}

Más allá de estas zonas relacionadas con las necesidades de las ciudades, pueden toclavía las iniciativas constructivas de los propietarios del terreno estar sujetas a otras limitaciones, como las servidumbres derivadas del plano de acondicionamiento regional, las de origen militar y otras.

En el plano de acondicionamiento regional que debería siempre estudiarse, y de un modo más detallado en regiones de intensa vida, donde existan núcleos urbanos de creciente desarrollo relativamente próximos, se indican, de acuerdo con las condiciones locales, las zonas y emplazamientos más convenientes para explotaciones agrícolas, foresıales, mineras y pecuarias; ins:alaciones industriales y colonias para los productores en ellas empleados; nuevos núcleos urbanos de otras clases y ensanches de los existentes; servicios públicos, como vías de comunicación, protección, captación y conducción de aguas potables, terrenos para la depuración biológica de las residuales; centrales eléctricas, fábricas de gas y sus conducciones, etcé era, y todo ello protegido higiénicamente y hermoseado por un sistema de espacios libres, pútlico y privado, cuya permanencia esté garantizada.

$\mathrm{Y}$ habiendo sido estos emplazamientos fijados de manera que cada uno sea el más adecuado para st1 especial destino, y no se perturben desde ellos las actividades que tendrán lugar en los demás, debemos procurar que, una vez aprobado un plano de acondicionamiento regional, no se levanten construcciones que pudiesen en su día entorpecer de una manera sensible su normal desarrollo.

916 Las grandes ciudades, rodeadas de otros núcleos urbanos de vida prós- 
pera, se ven obligadas a estudiar planos de conjunto que armonicen sus respectivos desarrollos. Es:os deben comprender a lo menos las zonas donde pueden residir o trabajar las personas empleadas que trabajan o viven en la ciudad, y cuyos diarios desplazamientos constituyen la llamada circulación pendular. La extensión de esta zona habitable será entonces función de la velocidad de los transportes de carácter colectivo. La extensión del plano regional de Berlín, preparado a principios del siglo, se limi:ó con una circunferencia de 25 kilómetros de radio, desde el centro de aquella capital. En el de Hamburgo, el radio es de 30 kilómetros; y en los recientes de París y Londres, de 35 y 40 kilómetros, respectivamente.

Las servidumbres impuestas con carácter de reglamentación general, o sea, como dice Prost, que se extiendan sobre todo el territorio de una región o de un Municipio, o de una o varias zonas, o a una o varias categorias de inmuebles, no deben crear derecho a indemnización, y así se admite generalmen'e. Pero si afectaran especialmente a algunas propiedades podrían causar perjuicios indemnizables. Lo mismo que si, al modificar unas ordenanzas que por haber sido aprobadas legalmente hubieran influído en el valor de los solares afectados, se redujera en las nuevas el aprovechamiento constructivo del terreno autorizado por aquéllas.

Servidumbre "non aedificandi".-Puede, como antes hemos indicado, tener esta servidumbre carácter permanente o temporal, como, respectivamen'e, en los cinturones verdes y en las zonas llamadas de terrenos reservados. Es'a servidumbre viene en alguros casos impuesta por prescripciones legales ajenas a la acción del Municipio, como la prohibición de edificar en determinadas zonas situadas alrededor de fortificaciones. En otros la imponen las condiciones del terreno; pendiente muy acentuada del mismo, excesiva profundidad del suelo firme u otras circusntancias que encarezcan extraordinariamente la edificación o perjudiquen sus condiciones higiénicas - terrenos húmedos o inundables, los de insuficiente insolación invernal, etc.

Esta servidumbre es fácil de aplicar cuando recae en terrenos de precio agrícola. Cuando la posibilidad de convertirse en edificable empieza a cotizarse, se justifica el derecho a la indemnización. En Alemania puede el Ayuntamiento verse obligado a comprar un terreno cuando la servidumbre que se le imponga disminuya en más de un 50 por 100 su valor; pero es as indemnizaciones son sólo abonables cuando los terrenos sean legal y prácticamente aptos para la edificación, cualidad que es el Ayuntamiento quien tiene la facultad de declarar. Otras disposiciones alemanas comple- $\mathbf{9 1 7}$ 
mentan la legislación, como la ley sobre propiedad hereditaria, que impide la libre disposición por pante del propietario de los terrenos dedicados a la agricultura, por razón de cargas, ventas o para cualquier otro uso distinto de aquél; la ley relativa al desarrollo de las zonas de parcelamiento obliga a que el fraccionamiento y la venta de terrenos comprendidos en ciertas zonas sean sometidos a la aprobación de las autoridades administrativas inferiores. Se impuṣo también la preparación de planos de zonización, determinando el uso del terreno.

La adquisición previa por los Ayuntamientos de terrenos agrícolas destinados a zonas de ensanche-Manchester, Estocolmo, etc.-soluciona directamente el problema, pues estas corporaciones sólo ceden a los constructores, a menudo sin venta, para evitar aumentos de valor del terrreno que encarezcan el alquiler de las viviendas y, por lo tanto, el coste de la vida, solares edificables según tipos de construcción determinados, quedando de su propiedad los espacios libres.

La ley inglesa, Town and Country Planning Aict, de 1932, propone declarar la zona afectada reserva agrícola temporal, y sólo permitir en ella construcciones que se ajusten a condiciones previamente determinadas. Se controla así el desarrollo de aquella zona, en la que, antes de que se produzca un cambio general, no se negará el permiso para levantar una construcción individual si no resulta que:

a) El precio que se obtenga por el terreno puede ser igualmente adquirido en los alrededores.

b) Là construcción puede perjudicar la higiene, por faltar calles, alcantarillas o cualquier otro servicio público; y

c) Oue la construcción no cause perjuicio al aspecto de la localidad.

Con la nueva ley se facilita la prohibición permanente de la edificación, sin reclamación de compensaciones, cuando por la situación o naturaleza de los terrenos la construcción de edificios sobre ellos lleva consiga peligro o daño para la salud, o causaría excesivo gasto público en la previsión de calles, instalaciones o servicios públicos en general.

Para conseguir resultados equitativos se han adoptado en Inglaterra los métodos siguientes, sugeridos por el Consejo para la Preservation of Rural England (véase "Town and Country Planning", por Patrik Abercrombie):

Método de la mancomunidad de incrementos.-Consiste en el establecimiento de mutuos acuerdos entre los propietarios de la zona afectada, con objero de que cuando en ella se reserven terrenos que permanezcan sin edificar, los propietarios de estos terrenos, desposeídos del valor de los destinados a la edificación, fuesen reembolsados por los poseedores de 918 aquellos en que se permita edificar. Para ello sería necesario una primera 
valoración, asignándose a los propietarios unas acciones de valor inmediato del conjunto de la región o unidad que resultase seleccionada. Se formaría una compañía local a base de los beneficios generales.

En otro método, la compensación a los propietarios privados de edificios tiene lugar mediante un fondo que se constituye con una tasa de mejora abonada por los demás propietarios, cuando el terreno esté en sazón para su desarrollo y pueda ser vendido para su edificación. Los terrenos se valorarán según su distancia al lugar de crecimiento de la ciudad, pagando la mejora según una escala progresiva. Como dicha mejora sólo se obtiene gradualmente, y la compensación sería reclamada inmediatamente, tendría que levantarse un préstamo sobre bases nacionales, utilizándose para el pago de los intereses aquellos valores de mejora.

Lugares de singular interés.-Cuando en las zonas que convenga reservar existan construcciones o aspectos del paisaje de singular interés, pueden aplicarse las leyes proyecioras de la belleza del país.

La ley española de 9 de agosto de 1926 protege los sitios o lugares de reconocida y peculiar belleza que reúnan determinadas condiciones.

En Francia, los lugares pintorescos son protegidos por la ley de 12 de mayo de 1930.

La ley de 15 de julio de 1907 permite en Alemania que se pueda denegar el permiso para "la ejecución o modificación de construcciones en las afueras de los lugares, si con ellas se afea en gran manera el paisaje". Por la ley sajona de 13 de enero de I934, cuyo reglamento es del día 17 del propio mes y año, referentes a la belleza del país, se protegen los monumentos artísticos, culturales y de la naturaleza, entendiéndose por tales "las cosas muebles o inmuebles cuya conservación, por su valor artístico, científico o típico, es de interés público". Pueden consistir los monumentos na'urales en interesantes o hermosas formas del terreno (colinas, lagunas, riberas, etic.), corrientes de agua, lagos, bosques, árboles o grupos de ellos, plantas de otras clases, yacimientos minerales, etc. La protección de los monumentos fijos en el terreno se extiende a sus alrededores en: lo conveniente para evitar que la transformación de éstos perjudique sus cualidades o la impresión que producen. Interesantes son también, en este sentido, la ley alemana de 26 de junio de 1935 y su reglamento de 3I de octubre del mismo año.

Desarrollo del ensanche de Roma.-Digno de èstudio, por la variedad de problemas cuya resolución facilitaba, es el utillaje legal de que disponía en 1935 el Ayuntamiento de Roma para impulsar ordenadamente el desarrollo de la ciudad.

Una ley de I I de julio de 1907 autorizaba al Municipio de aquella capital para expropiar los ternenos aptos para la construcción situados den- $01 \theta$ 
tro del perímetro de los planos de urbanización por el precio declarado por sus propietarios con motivo de los impuestos sobre el terreno.

Otra ley, de 24 de marzo de 1932 , número 355 , referente a la aprobación del plano de urbanización de Roma, completada por el decreto-ley de I7 de octubre de 1935, número I.987, facultaba al alcalde para encauzar del modo más favorable su desarrollo. Mediante es'as leyes podía el alcalde:

Prohibir la edificación donde no estuvieran todavía construídas las calles;

Declarar edificables los terrenos comprendidos en los planos señalados para la ejecución del plano de urbanización, y exentos por veinticinco años de los impuestos sobre la edificación a los propietarios que construyeran' nuevos edificios o modificaran los existentes en dichas zonas;

Expropiar toda la zona edificable comprendida en el plano.

Con estas facultades, el alcalde, valiéndose de una Oficina de Urbanismo, asesorada por un Comité de peritos:

Protegía las zonas a reservar, no construyendo en ellas ninguna calle;

Dirigía, por el orden más conveniente, la edificación en los sitios a ella destinados;

Estimulaba, mediante la condonación de tribuios, a los propietarios para que construyesen dentro de un plazo determinado;

Regularizaba fácilmente los terrenos mediante la expropiación o la amenaza de aplicarla, suprimiendo además las entorpecedoras parcelas inedificables; $y$, finalmente,

Castigaba a los propietarios de parcelas céntricas morosos en edificar, para venderlos a otros más diligenes, beneficiando con ello el aspecto dela vía pública, la economía en la urbanización de las calles y el ordenado des-arrollo del valor del terreno. 